\title{
Chondrocyte IGF-1 receptor expression and responsiveness to IGF-1 stimulation in mouse articular cartilage during various phases of experimentally induced arthritis
}

\author{
Pernette J Verschure, Jan van Marle, Leo A B Joosten, Wim B van den Berg
}

\begin{abstract}
Objective-To examine the distribution of insulin like growth factor-1 (IGF-1) receptors and the biological response to IGF-1 stimulation in articular cartilage of normal mouse knee joints and arthritic joints taken at various stages of experimentally induced arthritis.

Methods-In situ IGF-1 receptor expression and responsiveness to IGF-1 stimulation were examined in murine articular cartilage at different phases in two models of experimentally induced arthritis. IGF-1 receptor expression was visualised in joint sections with the use of anti-IGF-1 receptor antibodies and quantified by confocal laser scanning microscopy. Chondrocyte proteoglycan (PG) synthesis was measured by incorporation of ${ }^{35} \mathrm{~S}$-sulphate.
\end{abstract}

Results-In control cartilage, the majority of IGF-1 receptors were found on chondrocytes localised in the middle and deeper zones of the cartilage, whereas receptor expression in surface zone chondrocytes was very low. During culture of normal articular cartilage, IGF-1 was able to maintain chondrocyte PG synthesis at the in vivo level. Concurrently with the development of arthritis, cartilage lost its capacity to react to IGF-1, but IGF-1 stimulation recovered when the inflammatory response waned. Shortly after induction of arthritis, IGF-1 receptor expression initially declined, but it had returned to normal levels by day 1 and remained increased thereafter.

Conclusion-The distribution of IGF-1 receptor expression in the different zones of normal articular cartilage reflects IGF-1 stimulation and metabolic activity of chondrocytes in these layers. This correlation is disturbed in arthritic cartilage, suggesting inadequate or overruled signalling.

(Ann Rheum Dis 1995; 54: 645-653)

Destruction of articular cartilage is a prominent feature of inflammatory joint diseases such as rheumatoid arthritis (RA). ${ }^{1}$ The mechanism underlying tissue damage remains largely unknown. There is compelling evidence that products secreted by inflammatory cells, synovial lining cells, or chondrocytes themselves are responsible for loss of proteoglycans (PGs), denaturation of collagen, and chondrocyte death. The initial deterioration of the cartilage matrix is probably caused by disturbance of the equilibrium between synthesis and degradation of matrix PGs. ${ }^{2-4}$ It has been demonstrated that mediators such as interleukin-1 (IL-1) and tumour necrosis factor (TNF) are important inhibitors of chondrocyte PG synthesis, IL-1 being more potent than TNF. Furthermore, evidence is accumulating that these cytokines play a crucial role in the pathogenesis of arthritis. ${ }^{5-13}$ In addition, lack of anabolic signalling might contribute to decreased chondrocyte PG synthesis during joint inflammation. ${ }^{14} 15$

Insulin like growth factor-1 (IGF-1) is the most important growth factor that regulates cartilage PG synthesis. ${ }^{16-21}$ During culture, IGF-1 is able to maintain cartilage PG synthesis at the in vivo level. ${ }^{18-21}$ Moreover, selective elimination of IGF-1 from serum or synovial fluid with neutralising antibodies results in a marked decrease in cartilage PG synthesis, enhanced PG breakdown, and production of alternative PG sybtypes. ${ }^{21-23}$ IGF-1 regulates the synthesis of PG monomers with large dimensions in normal cartilage, whereas in arthritic cartilage the absence of induction of PG synthesis accompanies the preferential synthesis of PG monomers with only small dimensions. ${ }^{22} 23$ This indicates that IGF-1 non-responsiveness during arthritis also results in the production of alternative PG monomers, implying that IGF-1 is an essential signal to maintain cartilage integrity.

The biological actions of IGF-1 are mediated by high affinity binding to specific cell surface receptors, such as the IGF-1 type 1 and type 2 receptors. ${ }^{24-26}$ These receptors differ markedly in structure and peptide binding specificity. ${ }^{27}$ In general, IGF-1 binds preferentially with high affinity to the type 1 receptor, which is thought to be especially important in postnatal growth and development, ${ }^{28}$ while the type 2 receptor is considered to be a regulator of the glucose and energy metabolism and displays highest affinity for IGF-2. ${ }^{29}{ }^{30}$ IGF-2 is almost exclusively a fetal peptide and is considered to be particularly associated with organogenesis during embryonic development. $^{2730}$ The IGF-1 type 1 receptor is a

Correspondence to:

P J Verschure.

Accepted for publication

3 April 1995 
heterotetrameric glycoprotein, comprising two extracellular $\alpha$ subunits that are responsible for ligand binding and two $\beta$ subunits that span the cell membrane and contain tyrosine kinase activity in their cytoplasmic region. ${ }^{31} 32$

We reported previously that murine cartilage of knee joints at days 1 and 2 after induction of experimental arthritis displayed a state of non-responsiveness towards IGF-1 stimulation, which is not caused by a general impairment of the chondrocyte. ${ }^{1415}$ This suggests that inhibition of chondrocyte PG synthesis as found during joint inflammation is caused at least partly by a defect in IGF-1 signalling. There is little information available on IGF-1 receptor expression in normal and diseased cartilage. A recent study demonstrated increased IGF-1 receptor immunolocalisation on chondrocytes in human osteoarthritic (OA) cartilage, ${ }^{33}$ but data on arthritic cartilage are lacking.

In the present study we investigated IGF-1 receptor expression and the responsiveness to IGF-1 stimulation, examining patellar cartilage from normal and arthritic knee joints in two types of experimentally induced arthritis at various phases after induction of joint inflammation. The IGF-1 receptor was immunolocalised in different zones of the cartilage with the use of an antibody against IGF-1 type 1 receptor and visualised by both conventional fluorescence microscopy and confocal laser scanning microscopy (CLSM). In addition, receptor expression at the chondrocyte cell membrane was quantified on the basis of digital CLSM images, as described recently. ${ }^{34}$ The effect of IGF-1 on chondrocyte PG synthesis was measured by incorporation of ${ }^{35} \mathrm{~S}$-sulphate into mouse patellar cartilage.

\section{Materials and methods}

ANIMALS

Female C57 black/6 mice (8-12 weeks old, weights $20-25 \mathrm{~g}$ ) were studied. The animals were kept under routine laboratory conditions $\left(21-22^{\circ} \mathrm{C}\right.$, relative humidity $60 \%$ and a 12 hour light-dark cycle). They were fed a standard commercial pellet diet (RHM, Hope Farms, The Netherlands) and were given acidified tap water ad libitum.

\section{INDUCTION OF ARTHRITIS}

Arthritis was induced in mouse knee joints by two different methods. In the first, it was induced by intra-articular injection of yeast particles (180 $\mu \mathrm{g}$ sterilised zymosan (Sigma, St Louis, MO, USA) in pyrogen free saline) to right knee joints. This zymosan induced arthritis model is characterised by an early polymorphonuclear cell rich exudate in the joint space, loss of cartilage PGs, and inhibition of chondrocyte PG synthesis. Inflammation subsides within one week, and cartilage damage is reversible. ${ }^{414}$ In the second method, arthritis was induced with an antigen; this antigen induced arthritis, developing shortly after intraarticular injection of the antigen in previously immunised mice, is a more prolonged arthritis model than zymosan induced arthritis. ${ }^{4}$ Mice were immunised with $100 \mu \mathrm{g}$ methylated bovine serum albumin (mBSA, Sigma) emulsified in Freund's Complete Adjuvant (FCA) (Difco Laboratories, Detroit, MI, USA). Four equally large subcutaneous injections were given into the flank and footpads of the forelimbs. As an additional adjuvant, $2 \times 10^{9}$ heat killed Bordetella pertussis organisms (National Institute of Public Health, Bilthoven, The Netherlands) were injected intraperitoneally. After seven days, the immunisation was boosted with $100 \mu \mathrm{g}$ mBSA emulsified in FCA, divided over two equally large subcutaneous injections in the back. Arthritis was induced at day 21 by intra-articular injection of $60 \mu \mathrm{g}$ mBSA in $6 \mu l$ of phosphate buffered saline (PBS) into the right knee joint.

The antigen induced arthritis model is characterised by an acute synovial inflammation with numerous granulocytes, which changes into a chronic type of inflammation characterised by mononuclear cells. ${ }^{45}$ In common with zymosan induced arthritis, antigen induced arthritis is characterised in the acute phase of the disease by severe destruction of the cartilage matrix and inhibition of chondrocyte metabolism.

Left contralateral knee joints received no injections, and served as controls. It is known from previous studies that the contralateral joints show responses to the treatment that do not differ from the appearance of joints in control animals.

Mice were killed by cervical dislocation at 6 , $12,24,48,72,96$, or 168 hours after induction of arthritis and intact patellae were dissected from the right arthritic knee joints and left contralateral control knee joints. During the dissection process, the patellar ligaments were cut, but care was taken to leave the cartilage fully intact. ${ }^{436}$

JOINT INFLAMMATION

Joint inflammation was determined during different phases of arthritis by measurement of ${ }^{99 \mathrm{~m}} \mathrm{Tc}$-pertechnetate $\left({ }^{9{ }^{\mathrm{m}} \mathrm{Tc}} \mathrm{T}\right)$ uptake by the knee joint. Mice were sedated using chloralhydrate injected intraperitoneally, and ${ }^{99 \mathrm{~m}} \mathrm{Tc}$ was injected subcutaneously in the neck. After 20 minutes, radioactivity was measured in both knees, which were in a fixed position. Joint swelling was expressed as the ratio of the ${ }^{99 \mathrm{~m}} \mathrm{Tc}$ uptake in the right to that in the left knee joints (R:L ratio), ${ }^{37}$ a value greater than $1 \cdot 1$ indicating swelling.

\section{CARTILAGE CULTURES}

Patellae were cultured in an RPMI 1640 medium (Flow Laboratories, Irvine, Scotland) containing $2 \mathrm{mmol} / \mathrm{l}$ glutamine, $40 \mu \mathrm{g} / \mathrm{ml}$ gentamycin, $0 \cdot 1 \%$ ultrapure BSA (Sigma), with or without addition of $0.25 \mu \mathrm{g} / \mathrm{ml}$ recombinant human IGF-1 (Boehringer, Mannheim, Germany). The molarity of $0.25 \mu \mathrm{g} / \mathrm{ml}$ IGF- 1 is $4.38 \times 10^{-8}$. All incubations were performed over 24 hours in 24 well cluster dishes at $37^{\circ} \mathrm{C}$ in a humidified atmosphere containing $5 \%$ carbon dioxide. 
PROTEOGLYCAN SYNTHESIS IN VITRO

Chondrocyte PG synthesis in patellar cartilage of control joints and of knee joints during different phases of arthritis was measured by the incorporation of ${ }^{35} \mathrm{~S}$-sulphate as described previously. ${ }^{36}{ }^{38}$ Briefly, cartilage was cultured in RPMI 1640 medium containing $0 \cdot 1 \%$ BSA, glutamine and gentamycin in the presence of $6 \mathrm{MBq}{ }^{35} \mathrm{~S}$-sulphate $\left(\mathrm{Na}^{35} \mathrm{SO}_{4}\right.$, Amersham, Buckinghamshire, UK) for two hours at $37^{\circ} \mathrm{C}$. This was done both immediately after isolation of intact patellae to estimate the in vivo level of proteoglycan synthesis, and after a 24 hour culture period to estimate the level of proteoglycan synthesis after culture. Afterwards, tissues were washed three times with PBS to remove non-incorporated ${ }^{35} \mathrm{~S}$-sulphate. Patellae were subsequently fixed in $96 \%$ ethanol and decalcified in $5 \%$ formic acid for three hours, followed by stripping of the articular cartilage layer from the remainder of the patellae. The patellar cartilage was digested in Lumasolve (Perstop Analytical, Oud Beyerland, The Netherlands) at $60^{\circ} \mathrm{C}$. The quantity of incorporated radioactive sulphate in each patella was assayed by liquid scintillation counting.

PREPARATION OF TISSUE FOR

IMMUNOHISTOCHEMISTRY

Patellae were embedded in $8 \%$ gelatin white (Sigma) in distilled water, frozen in liquid nitrogen and cryostat sections of the frozen mouse patellae were cut $(7 \mu \mathrm{m}$ thick) on a motor driven Bright cryostat fitted with a microtome with a tungsten carbide tipped knife at a cabinet temperature of $-25^{\circ} \mathrm{C}$, and attached to adhesive tape (Scotch tape 800, $3 \mathrm{M}$, St Paul, $\mathrm{MN}$ ). ${ }^{39-43}$ Sections were kept dry over silica gel and stored at $-25^{\circ} \mathrm{C}$ until required for further use.

\section{IMMUNOHISTOCHEMISTRY}

Cryostat sections were fixed for 10 minutes in 4\% paraformaldehyde (Sigma) in PBS, $\mathrm{pH}$ $7 \cdot 4$, and subsequently washed in PBS containing 10\% BSA (Sigma), 10\% gelatin and $0.3 \%$ glycine (Pharmacia, Upsala, Sweden). They were then incubated for 30 minutes at $37^{\circ} \mathrm{C}$ in a solution of $2 \mathrm{mg} / \mathrm{ml}$ testicular hyaluronidase (Sigma) in PBS to improve antibody penetration into the cartilage matrix. Thereafter, sections were washed in PBS, incubated for 30 minutes in PBS containing 10\% fetal calf serum and $1 \% \mathrm{BSA}$ in PBS and then for 24 hours at $4^{\circ} \mathrm{C}$ in the presence of the primary antibody in a concentration of $5 \mu \mathrm{g} / \mathrm{ml}$ in PBS in the presence of $1 \%$ BSA. Polyclonal rabbit antihuman type $1 \mathrm{IGF}-1$ receptor antibody was obtained from UBI (New York, NY, USA); it recognises mouse type 1 IGF-1 receptor. ${ }^{44} 45$ Sections were then washed in PBS and incubated with biotinylated goat antirabbit secondary antibody (Vector Laboratories, Burlingame, USA) for one hour in a dilution of $1: 500$ in PBS in the presence of $1 \% \mathrm{BSA}$ and $1 \%$ normal mouse serum. Thereafter, they were washed in PBS and exposed to streptavidin-fluorescein isothiocyanate (Boeh- ringer) in a concentration of $5 \mu \mathrm{g} / \mathrm{ml}$ in PBS. Subsequently, the slides were mounted in glycerol-phenylenediamine solution (Sigma) to prevent fading of the fluorescence, and kept at $-25^{\circ} \mathrm{C}$ until evaluation using CLSM. Control sections were incubated either with an IgG fraction of normal rabbit serum used in the same dilution as the primary antibody, or in the absence of primary antibody.

CLSM EVALUATION AND IMAGE ANALYSIS

Immunolabelled cryostat sections were examined with a Leica CLSM in combination with a Leica Fluovert microscope using the $488 \mathrm{~nm}$ line of an Argon Krypton laser as described in an earlier study. ${ }^{34}$ The CLSM collects images that are almost free from out of focus signals, and the system allows optical sectioning of the specimen. ${ }^{46-48}$ Sections were subjected to optical sectioning and the immunofluorescence signal was quantified. Quantification of immunofluorescence intensity in the confocal images was determined by area measurement at the chondrocyte periphery. ${ }^{34}$ To assess the contribution of autofluorescence and nonspecific binding, the fluorescence signal in sections stained with control non-immune serum was also measured.

Chondrocytes were assessed in the deep, middle, and surface zones of the cartilage. The average fluorescence intensity was expressed as percentage of the mean fluorescence intensity of chondrocytes in the control cartilage. Statistical evaluation of the experiments was performed with the Wilcoxon rank test. A value of $p$ less than $5 \%$ was considered significant.

\section{Results}

CHONDROCYTE PG SYNTHESIS AND JOINT INFLAMMATION

When normal patellae were cultured for 24 hours in media without serum or growth factors, chondrocyte PG synthesis declined to approximately $50 \%$ of that immediately after dissection of the cartilage. ${ }^{14}$ Culturing cartilage for 24 hours in the presence of $0 \cdot 25-2 \cdot 0 \mu \mathrm{g} / \mathrm{ml}$ IGF-1 induced a significant, dose dependent stimulation of chondrocyte PG synthesis (fig 1). In all other experiments we used $0.25 \mu \mathrm{g} / \mathrm{ml}$ IGF-1, which maintained PG synthesis of normal cartilage at in vivo levels, and which is close to the physiological concentration of IGF-1 in mouse tissues. ${ }^{21} 49$

Six hours after the onset of zymosan induced arthritis, the ex vivo chondrocyte PG synthesis remained at the same level as found in control cartilage and no enhanced R:L ratio of ${ }^{99 \mathrm{~m}} \mathrm{Tc}$ uptake, reflecting joint swelling, was observed (fig 2A, B). Within 12 hours of induction of arthritis, the ex vivo PG synthesis of arthritic cartilage decreased to approximately $80 \%$ of the levels of ${ }^{35} \mathrm{~S}$-sulphate incorporation in control cartilage, whereas at 24-72 hours after induction incorporation of ${ }^{35} \mathrm{~S}$-sulphate into arthritic cartilage was markedly reduced, to approximately $50 \%$ of the normal PG synthesis. Joint swelling was observed within 12 hours of the induction of zymosan induced 


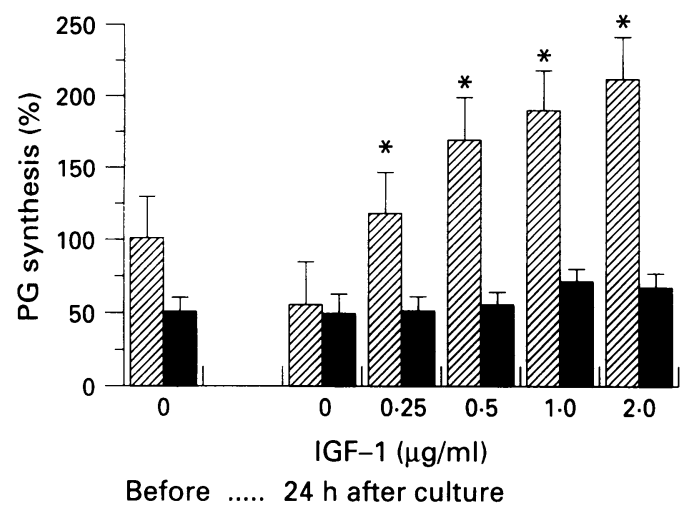

Figure 1 In vitro response to IGF-1 stimulation of normal $(\square)$ and zymosan induced arthritic ( $\square$ ) articular

cartilage of mice: chondrocyte PG synthesis determined by

${ }^{35} S$-sulphate incorporation either immediately after isolation of the patellae $(t=0)$ or after 24 hours culture in media containing 0-2.0 $\mu \mathrm{g} / \mathrm{ml} I G F-1$. Data represent the mean (SEM) of three experiments, expressed as percentage of the control value at $t=0$.

${ }^{*} p<0.05$ compared with control.

arthritis, reached a maximum at 24 hours, and disappeared at four days after induction (fig 2B). At day 4, the inflammatory response waned and chondrocyte PG synthesis in the arthritic cartilage became restored. Concurrently with the development of zymosan induced arthritis (reduction of PG synthesis in the arthritic cartilage and enhancement of joint swelling), the arthritic cartilage lost its capacity to respond to IGF-1 in a 24 hour culture system (fig $2 \mathrm{C}$ ), even supraphysiologically high concentrations $(2 \cdot 0 \mu \mathrm{g} / \mathrm{ml})$ of IGF-1 failing to induce stimulation of PG synthesis (fig 1). Four days after induction of arthritis, recovery of IGF-1 responsiveness was observed in the arthritic cartilage (fig 2C).
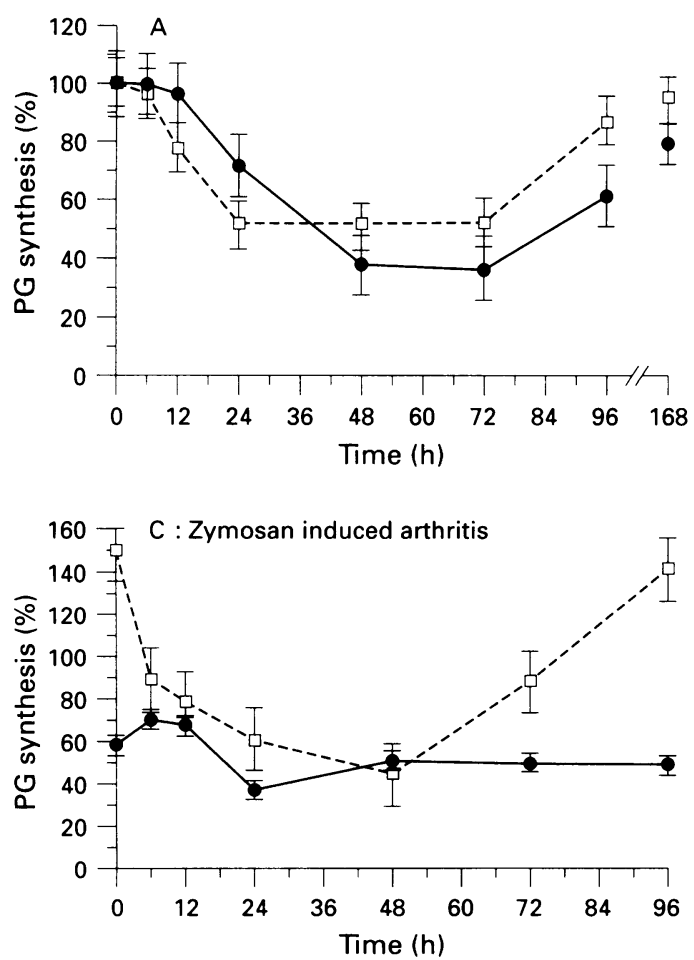

After antigen induced arthritis, a somewhat different response was observed. Significant inhibition of PG synthesis in the arthritic cartilage was first observed one day after induction of arthritis, suppression was more pronounced at days 2 and 3 , and recovery of PG synthesis appeared to be retarded (fig 2A). An enhanced R:L ratio of ${ }^{99 \mathrm{~m}} \mathrm{Tc}$ uptake was noted 24 hours after antigen induced arthritis. Maximal joint swelling was reached within three to four days after induction of arthritis, and swelling began to disappear seven days after the induction of arthritis (fig $2 \mathrm{~B}$ ). This is consistent with the significantly more prolonged form of arthritis represented in the antigen induced arthritis model as compared with the zymosan induced arthritis model. ${ }^{4}{ }^{14}$ IGF-1 stimulation of chondrocyte PG synthesis in the arthritic cartilage disappeared during the manifestation of arthritis in the antigen induced arthritis model and was still not restored at day 4 (fig 2D). As shown for the zymosan induced arthritis model, high concentrations of IGF-1 were unable to induce stimulation of PG synthesis in the antigen induced arthritis model (data not shown).

\section{IMMUNOHISTOCHEMICAL LOCALISATION OF} IGF-1 RECEPTOR IN NORMAL CARTILAGE Conventional fluorescence microscopical evaluation of mouse patellar cartilage sections stained immunohistochemically to demonstrate IGF-1 type 1 receptor revealed the presence of the IGF-1 receptor in chondrocytes within the articular cartilage, whereas the cartilage matrix was negative (fig $3 \mathrm{~A}$ ). Immunoreactivity was present on the
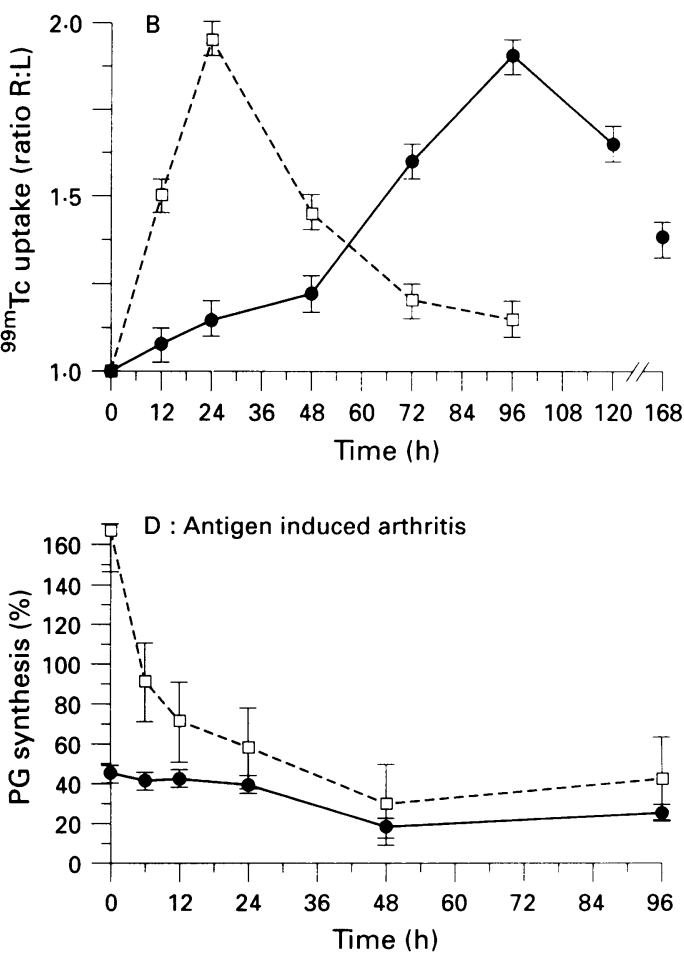

Figure 2 Proteoglycan synthesis (measured as incorporation of ${ }^{35} S$-sulphate) in patellar cartilage immediately after isolation of the cartilage $(A)$ and after culture for 24 hours in the presence or absence of $I G F-10 \cdot 25 \mu \mathrm{g} / \mathrm{ml}(C, D)$; the contralateral patellar cartilage was used as control. B: Foint swelling, expressed as ratio of ${ }^{99 m} T c$ uptake in the right and left knee joints. Data represent the mean of at least two experiments and are mean (SEM) of five patellae in each group. $A, B: \square=$ zymosan induced arthritis; $=$ antigen induced arthritis. $C, D: \square=I G F-1 ; 0=$ no IGF-1. 


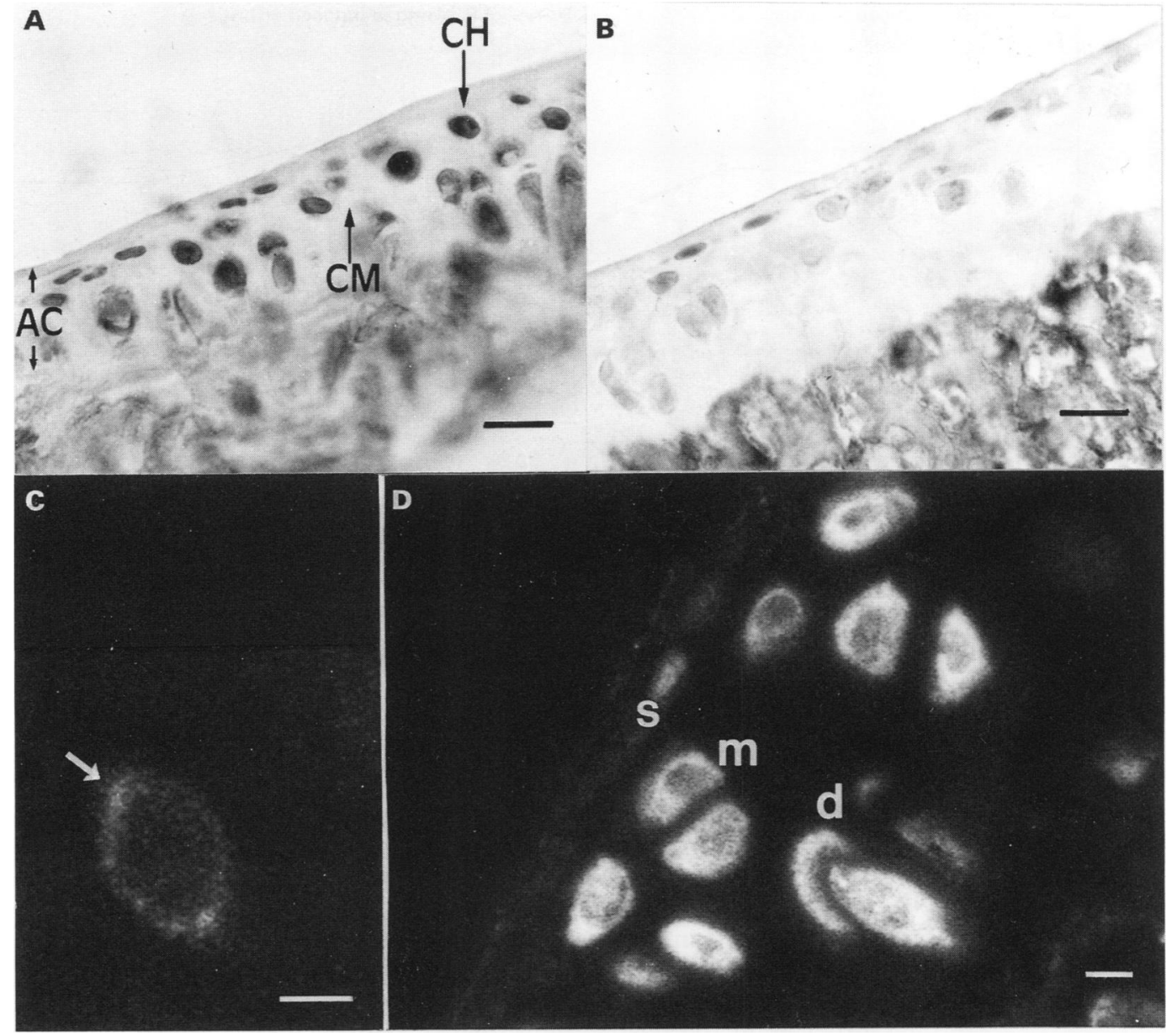

Figure 3 IGF-1 receptor immunolocalisation in mouse normal patellar cartilage. A: Light microscope evaluation of the immunolocalisation of $I G F-1$ receptor. Chondrocytes $(C H)$ within the articular cartilage $(A C)$ distinctly stained, but cartilage matrix (CM) staining negative. Bar represents $21 \cdot 1 \mu \mathrm{m} . \quad$ B: Light microscope evaluation of control staining with non-immune serum. Background negligible compared with anti-IGF-1 receptor staining. Bar represents $21 \cdot 1 \mu m$. C: Confocal laser scanning microscope (CLSM) evaluation of the middle optical section through the depth of the chondrocyte. The chondrocyte membrane contains intense IGF-1 receptor immunoreactivity (arrow). Bar represents $3.5 \mathrm{\mu m}$. D: Overview of immunolocalisation of IGF-1 receptors on chondrocytes located in different zones of mouse cartilage as visualised by CLSM. Chondrocytes located in the middle $(m)$ and deeper $(d)$ zones show bright positive staining, whereas staining of chondrocytes in the surface zone (s) is similar to background fluorescence. Bar represents $1 \cdot 3 \mu \mathrm{m}$.

chondrocyte cell surface, but a diffuse intracellular staining was also observed, and diffuse autofluorescence was found over the entire cartilage area. Background staining in sections that were treated with non-immune rabbit serum was negligible in comparison with antiIGF-1 receptor staining (fig $3 \mathrm{~B}$ ). With conventional fluorescence microscopy it was impossible to determine exact amounts of IGF-1 receptor immunoreactivity on the chondrocyte plasma membrane. Evaluation with CLSM showed that the chondrocyte membrane contained intense IGF-1 receptor immunoreactivity (fig 3C), and allowed for exact measurement of non-immune serum and $\alpha \mathrm{IGF}-1$ receptor fluorescence signal (fig 3D). Non-specific fluorescence and autofluorescence caused a constant level of background fluorescence in all cartilage layers which was consistent in all experiments. IGF-1 receptor immunostaining on the chondrocyte cellular membrane was observed in particular in chondrocytes of the middle and deeper zones of the cartilage, whereas chondrocytes in the surface zone did not show any significant specific staining for these receptors (fig 3D). Chondrocytes in surface zones displayed a fluorescence intensity similar to the background fluorescence.

IMMUNOHISTOCHEMICAL LOCALISATION OF IGF-1 RECEPTOR IN ARTHRITIC CARTILAGE

Zymosan induced arthritis. Quantification of the fluorescence intensity on chondrocyte cell membranes revealed that, at six hours after induction of arthritis, chondrocytes in the deeper zones still displayed normal fluorescence intensity, while those located in the middle zone exhibited a reduced fluorescence signal compared with chondrocytes in the middle zone of control cartilage (fig 4A). Within 12 hours of induction of arthritis, fluorescence intensity in both middle and deeper zones was significantly reduced compared with that in control cartilage (figs $4 \mathrm{~A}, 5 \mathrm{~A}$ ). At 24 hours after induction of arthritis, the same low levels of immunofluorescence staining were found, and at 48 hours, chondrocytes located in both middle and deeper zones showed IGF-1 receptor immunoreactivity similar to that in control cartilage; this remained constant until the end of the period of study (fig $4 \mathrm{~A}$ ). 

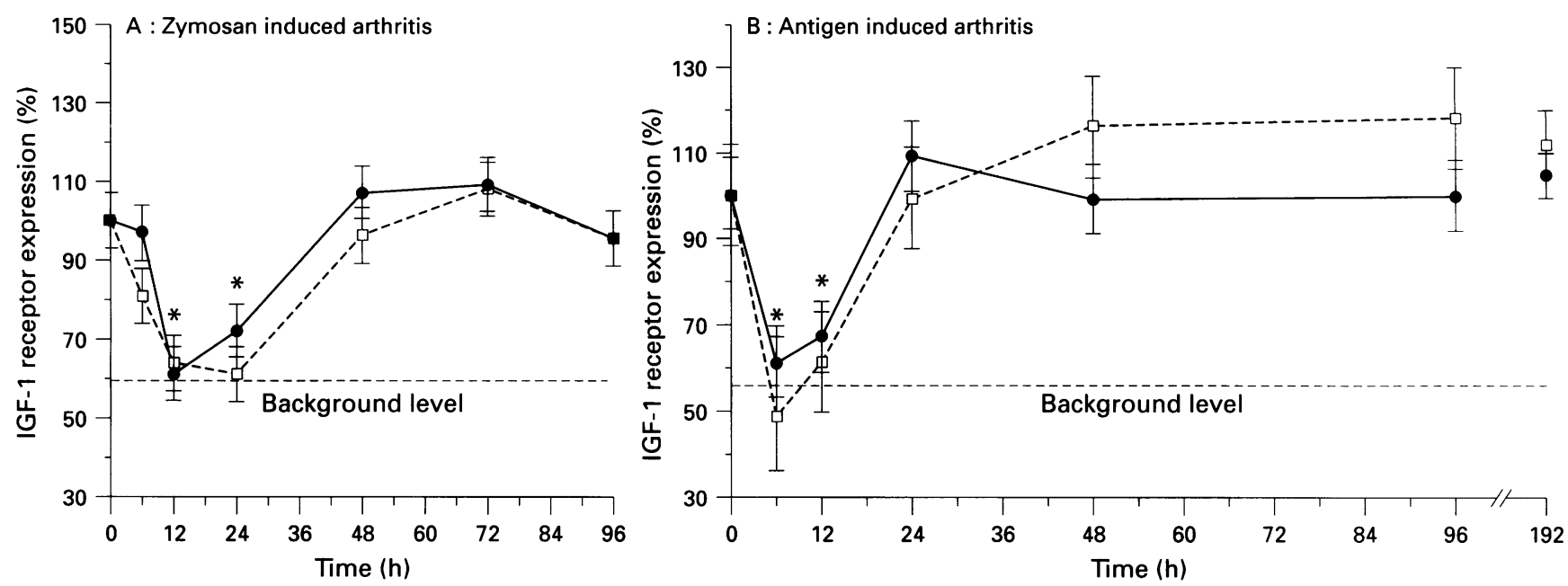

Figure 4 Quantification of IGF-1 receptor immunoreactivity in mouse patellar cartilage middle ( $\square$ ) or deep (O) zones at various stages of either zymosan induced arthritis $(A)$ or antigen induced arthritis (B). Data are mean (SEM) of three independent experiments expressed as percentage of the intensity detected in chondrocytes located in the same cartilage zones of normal cartilage. Background level $=$ fluorescence signal in sections stained with control non-immune serum.

${ }^{*_{p}}<0.05$ between zones (Wilcoxon rank test).

Antigen induced arthritis. In contrast with findings in patellae after zymosan induced arthritis, significant low immunoreactivity was already evident six hours after induction of arthritis by antigen (figs $4 \mathrm{~B}, 5 \mathrm{~B}$ ). Surprisingly, 24 hours after antigen induction of arthritis, IGF-1 receptor staining had returned to normal levels in chondrocytes of both middle and deep layers. From this phase of the arthritis onwards, immunoreactivity in chondrocytes in the deeper zones of the cartilage remained constant at the level of that in control cartilage. Chondrocytes in the middle zones showed a slight but not significant increase in fluoresence intensity. At day 7 after induction of arthritis, IGF-1 receptor immunoreactivity in chondrocytes of both zones had returned to the levels found in control cartilage.

\section{Discussion}

IGF-1 is known to have a key role in the regulation of chondrocyte biosynthetic functions, ${ }^{16}{ }^{18-21}$ and lack of anabolic signalling during arthritis ${ }^{1433}$ (fig 1) may contribute to cartilage destruction. In the present study we have shown that distribution patterns of IGF-1 receptor expression in the different zones of normal cartilage may reflect IGF-1 stimulation and metabolic activity of chondrocytes in these layers. Concurrently with the development of arthritis, cartilage lost its capacity to react to IGF-1, but when the inflammatory response was waning, IGF-1 stimulation had recovered. Shortly after induction of experimental arthritis a clear decrease in IGF-1 receptor expression was observed, whereas in later phases of arthritis, receptor expression returned rapidly to normal levels.

In a previous study we showed that nonresponsiveness to IGF-1 stimulation occurred at days 1 and 2 after induction of experimental arthritis. ${ }^{14}$ These results, together with those outlined above, indicate that the phenomenon of IGF-1 non-responsiveness is highly correlated with the severity of arthritis. ${ }^{4}$ The early

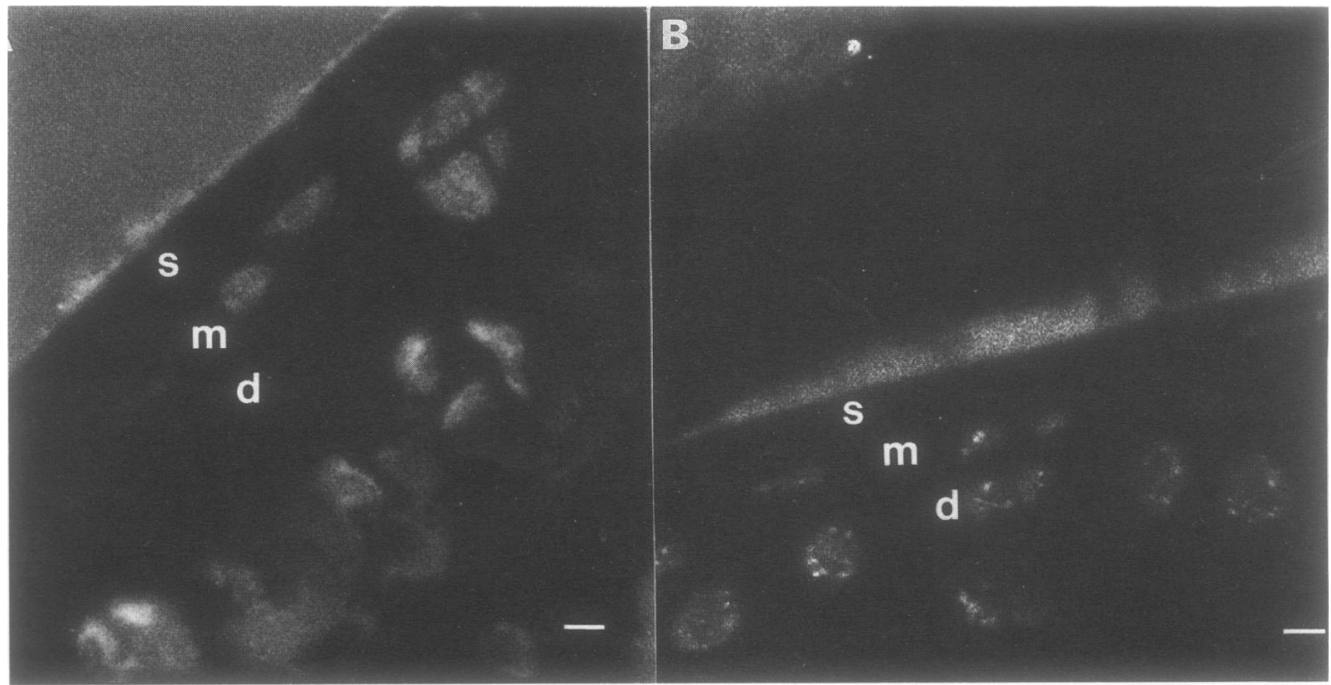

Figure 5 IGF-1 receptor immunolocalisation in cryostat sections of surface $(s)$, middle $(m)$ and deep (d) zones of mouse patellar cartilage at various phases of either zymosan induced arthritis $(A)$ or antigen induced arthritis $(B)$, visualised by confocal laser scanning microscopy. Bars represent $1 \cdot 3 \mu \mathrm{m}$. A: Twelve hours after zymosan induced arthritis; weak $I G F-1$ receptor immunoreactivity in zones $s, m$, and $d$, compared with cartilage from control joints. B: Six hours after the onset of antigen induced arthritis; low IGF-1 receptor immunoreactivity in zones $s, m$, and d, compared with the

fluorescence intensity found in control cartilage. 
start of IGF-1 non-responsiveness in zymosan induced arthritis, and the later recovery in antigen induced arthritic cartilage, are consistent with the early onset of zymosan induced arthritis and the more prolonged inflammation in antigen induced arthritis.

In our analysis of IGF-1 receptor expression, CLSM optical sectioning of sections after immunolocalisation of IGF-1 receptor allowed accurate localisation and quantification of the immunoreactivity in the chondrocyte cell membrane. ${ }^{34}$ The majority of IGF-1 receptor immunoreactivity was localised in chondrocytes of the middle and deeper zones of control cartilage, while it was very low in chondrocytes of the surface zone (fig 5). It is known that chondrocytes in the middle and deeper zones of human, pig, and bovine cartilage display greatest metabolic activity, whereas the metabolic activity of superficial chondrocytes is very low. ${ }^{50-53}$ On the basis of our data it may be concluded that differences in IGF-1 receptor expression in the cartilage layers are correlated with the heterogeneity in IGF-1 stimulation and activity of the chondrocytes in these layers.

Data also exist that indicate that alterations in chondrocyte metabolism under pathophysiological conditions also are not uniform in the different zones. ${ }^{54} 55$ In human OA cartilage, high levels of IGF-1 and IGF-1 mRNA have been described, especially in chondrocytes located in clones at the surface zone. ${ }^{56}$ Furthermore, it has been shown that human OA cartilage was abundantly stained for IGF-1 receptor in the upper two thirds of the cartilage. ${ }^{33}$ It should be noted that PG synthesis is at a high level in osteoarthritic cartilage, in contrast with arthritic cartilage.

In view of our data, it may be questioned which factors account for the decrease in IGF-1 receptor expression shortly after induction of arthritis. Under normal conditions, IGF-1 receptor expression is regulated on the basis of receptor occupancy: receptors are rapidly internalised and down regulated after IGF-1 binding. ${ }^{57} 58$ It remains a matter of speculation whether and how inflammatory mediators are involved in the reduction of IGF-1 receptors during the early stages of arthritis. Many plasma membrane receptors such as antigen binding molecules, adhesion molecules, and cytokine receptors have been reported to decrease in number during inflammation, by shedding. ${ }^{59}$ Porteu et al ${ }^{60}$ suggested that shedding of TNF receptors on activated polymorphonuclear cells might be the result of cleavage by proteases released from inflammatory cells or by chondrocytes themselves. ${ }^{61-63}$ We have shown previously that oxygen radicals produced by cells in the inflamed synovium are unlikely to be involved because they were unable to damage IGF-1 receptors in vitro. ${ }^{64}$ The early loss of receptors coincides with a rapid decline in proteoglycan content, which may indicate that it is caused by the same proteolytic enzymes released into the extracellular matrix cartilage.

The apparent discrepancy between low levels of IGF-1 receptor expression in cartilage from joints in early stages of arthritis and normal responses to IGF-1 at these phases of arthritis may be explained by the time needed for the translation of IGF-1 receptor binding into changes of chondrocyte PG synthesis. A lag phase of approximately eight hours has been reported. ${ }^{65}$ Moreover, PG synthesis is measured after a 24 hour culture period, and it is likely that in these early stages of arthritis the chondrocytes may recover during culture and upregulate the amount of IGF-1 receptors on their cell membranes. At present, recovery of receptor expression after culture is under investigation in our laboratory, and preliminary data have shown a recovery of receptor expression in cartilage at early stages of arthritis. In addition, we are now analysing potential changes in mRNA expression of the IGF-1 receptor during early phases of arthritis, using polymerase chain reaction technology.

Our observation that, at later stages of arthritis, amounts of IGF-1 receptors rapidly returned to normal levels, while inhibition of PG synthesis continued, suggest that at this phase of arthritis the IGF-1 signal is overruled by suppressive mediators generated by the inflamed synovium. Otherwise, the type I receptor might be masked or damaged by agents produced by the inflamed synovium, preventing correct binding of IGF-1. Alternatively, but speculatively, the IGF-1 receptors present on the chondrocyte cell surface during later phases of arthritis may have a defective molecular structure, being therefore unable to exhibit normal biological functions.

Taking into consideration our present results and those of previous studies, ${ }^{1415}$ we suggest that IGF-1 non-responsiveness may play a part in perpetuating inhibition of chondrocyte PG synthesis. Moreover, non-responsiveness of arthritic chondrocytes is not restricted to IGF-1, but also extends to a range of other growth factors: basic fibroblast growth factor, platelet derived growth factor, epidermal growth factor, or transforming growth factor $\beta$, in the presence or absence of IGF-1, were unable to stimulate chondrocyte PG synthesis during early and later phases of arthritis. ${ }^{66} \mathrm{It}$ remains unclear which mediators are involved in IGF-1 non-responsiveness during experimentally induced arthritis. Intra-articular injection of IL-1 into mouse knee joints caused inhibition of chondrocyte PG synthesis and enhanced PG breakdown, but did not induce IGF-1 non-responsiveness, ${ }^{7-9} 67$ and in cartilage obtained from arthritic knee joints and cultured with anti-IL-1 neutralising antibodies, the state of IGF-1 non-responsiveness was not completely abrogated. ${ }^{9}$ However, normal IGF-1 responsiveness was observed in arthritic cartilage when anti-IL-1 treatment was started in vivo, before induction of arthritis. These observations imply that IL-1 plays an indirect or subordinate part in IGF-1 non-responsiveness. Alternatively, increased IGF-1 binding protein (IGFBP) production may cause IGF-1 non-responsiveness during experimentally induced arthritis. ${ }^{68}{ }^{69}$ Dore et al reported that, during osteoarthritis, articular chondrocytes produce increased levels of IGFBP. ${ }^{33}$ In our experimental design, 
decreased IGF-1 bioactivity could occur when tissue IGFBP production is increased. However, we found IGF-1 non-responsiveness even at high IGF-1 concentrations, making IGFBP overproduction an unlikely explanation for the lack of IGF-1 response during inflammation.

In conclusion, we have shown that distribution patterns of IGF-1 receptor expression in the different zones of normal cartilage reflect IGF-1 stimulation and metabolic activity of chondrocytes in these layers. However, our data do not reveal a straightforward correlation between receptor expression and biological response of chondrocytes from arthritic cartilage. The present study thus seems to imply that caution should be taken in drawing conclusions from receptor expression investigations without evaluating the biological responses triggered by receptor binding.

The authors wish to thank Henk Van Veen, Jan Peterse, Rob Lutgerhorst and Monique Helsen for excellent technical assistance and Dr Cornelis J F Van Noorden for critical review of the manuscript. This study was supported by TNO.

1 Zvaifler N J. Pathogenesis of the joint disease of rheumatoid arthritis. Am $\mathcal{F}$ Med 1983; 75 (suppl 3).

2 Krane S M, Amento E P, Goldring S R. Cellular interactions in tissue breakdown in rheumatoid arthritis. Adv Inflamm Res 1986; 51: 1-12

3 Sandy J D, Lowther D A, Brown H L G. Antigen-induced arthritis: studies on the inhibition of proteoglycan synthesis observed in articular cartilage during short-term synthesis observed in articular cartilage during short-te

4 Van den Berg W B, Kruijsen M W M, Van de Putte L B A, Zwarts W A. Antigen-induced arthritis and zymosan-induced arthritis in mice: Studies on in vivo cartilage proteoglycan synthesis and chondrocyte death $B r \mathcal{F}$ Exp Pathol 1981; 62: 308-16.

5 Tyler J A, Saklatvala J. Pig interleukin-1 (catabolin) induces resorption of cartilage and prevents synthesis of proteoglycan and collagen. Br $\mathcal{F}$ Rheumatol 1985; 24 (suppl 1): $150-5$.

6 Benton H P, Tyler J A. Inhibition of cartilage proteoglycan synthesis by interleukin-1. Biochem Biophys Res Commun 1988; 145: 421-8.

7 Van de Loo A A J, Van den Berg W B. Effects of murine recombinant IL-1 on synovial joints in mice: quantification of patellar cartilage metabolism and join inflammation. Ann Rheum Dis 1990; 49: 238-45.

8 Van de Loo A A J, Van Beuningen H M, Van Lent P L M, Van den Berg W B. Direct effect of murine rIL-1 on cartilage metabolism in vivo. Agents Actions 1989; 26: 153-5.

9 Van de Loo A A J, Arntz O J, Otterness I G, Van den Berg W B. Protection against cartilage proteoglycan synthesis inhibition by anti-interleukin 1 antibodies in experimental arthritis. F Rheumatol 1992; 19: 348-56.

10 Verschure $P$ J, Van Noorden C J F. The effects of interleukin-1 on articular cartilage destruction as observed in arthritic diseases, and its therapeutic control. Clin Exp Rheumatol 1990; 8: 303-13.

11 Van Beuningen H M, Arntz O J, Van den Berg W B. In vivo effects of interleukin-1 on articular cartilage: prolongation of proteoglycan metabolic disturbance in old mice. Arthritis Rheum 1991; 34: 606-15.

12 Saklatvala J. Tumor necrosis factor- $\alpha$ stimulates resorption and inhibits synthesis of PG in cartilage. Nature 1987 332: 547-9.

13 Saxne $T$, Palladino $M$ A, Heinegard D Jr, Talal $N$, Wollheim F A. Detection of tumor necrosis factor $\beta$ in rheumatoid arthritis synovial fluid and serum. Arthritis Rheum 1988; 31: 1041-5.

14 Schalkwijk J, Joosten L A B, Van den Berg W B, Van de Putte L B A. Chondrocyte nonresponsiveness to insulinPutte L B A. Chondrocyte nonresponsiveness to insulinlike growth factor 1 in

15 Van den Berg W B, Joosten L A B, Schalkwijk J, Van de Loo F A J, Van Beuningen H M. Mechanism of cartilag destruction in experimental arthritis: lack of IGFresponsiveness. In: Lewis A, Doherty N S, Ackeman $\mathrm{N}$ R, eds. Therapeutic approaches to inflammatory diseases. New York: Elsevier Science, 1989; 47-54.

16 Tyler J A. Insulin-like growth factor 1 can decrease degradation and promote synthesis of proteoglycan in cartilag exposed to cytokines. Biochem 7 1989; 260 : 543-8.

17 Isaksson O G, Ohlsson C, Nilsson A, Isgaard J, Lindahl A. Regulation of cartilage growth by growth hormone and insulin-like growth factor 1. Pathology 1991; 5: 451-3.

18 Hascall V C, Handley C J, McQuillan D J, Hascall G K, Robinson H C, Lowther D A. The effect of serum on biosynthesis of proteoglycans by bovine articular cartilag in culture. Arch Biochem Biophys 1983; 224: 206-23.
19 Luyten F P, Hacall V C, Nissley S P, Morales T I, Reddi A H. Insulin-like growth factors maintain steadystate metabolism of proteoglycans in bovine articular state metabolism of proteoglycans in bovine articular

20 McQuillan D J, Handley C J, Campbell M A, Bolis S Milway V E, Herrington A C. Stimulation of proteoglycan synthesis by serum and insulin-like growth factor-1 in cultured bovine articular cartilage. Biochem $\mathcal{f} 1986 ; 240$ 424-30.

21 Schalkwijk J, Joosten L A B, Van den Berg W B, Wijk J J, Van de Putte L B A. Insulin-like growth factor stimulation of chondrocyte proteoglycan synthesis by human synovial fluid. Arthritis Rheum 1989; 32: 66-71.

22 Van der Kraan P M, Vitters E L, Verbunt J, Van den Berg W B. Maintenance of the synthesis of large proteoglycans in anatomically intact murine articular cartilage by in anatomically intact murine articular cartilage by 1993; 52: $734-41$.

23 Verschure P J, Van der Kraan P M, Vitters E L, Van den Berg W B. Stimulation of proteoglycan synthesis by triamcinolone and insulin-like growth factor in normal and arthritic murine articular cartilage. $\mathcal{F}$ Rheumatol 1994 21: $920-5$.

24 Demarquay D, Dumontier M F, Tsagris L, Bourguigon J, Nataf V, Corvoll M T. In vitro insulin-like growth factor interaction with cartilage cells derived from postnatal animals. Hormone Res 1990; 33: 111-4.

25 Froesch E R, Schmid C, Schwander J, Zapf J. Actions of insulin-like growth factor. Ann Rev Physiol 1985; 47: 443-67.

26 Neely E K, Beukers M W, Oh Y, Cohen P, Rosenfeld R G. Insulin-like growth factor receptors. Acta Paediatr Scand 1991; 372: 116-23.

27 Le Roith D, Raizada M K. Molecular and cellular biology of insulin-like growth factors and their receptors. New York: Plenum Press, 1989

28 Trippel S B, Chernausek S D, Van Wijk J J, Moses A C Mankin H J. Demonstration of type 1 and type 2 somatomedin receptors in bovine growth plate chondrocytes. F Orthop Res 1988; 6: 817-26.

29 Baumick B, Bala R M. Differential effects of insulin-like growth factors 1 and 2 on growth, differentiation and glucoregulation in differentiating chondrocyte cells in culture. Acta Endocrinol 1991; 125: 201-11.

30 Daughaday W H, Rotwein P. Insulin-like growth factor and 2 peptide messenger ribonucleic acid and gene tructures, serum and tissue concentrations. Endocrine Rev 1989; 10: 68-91.

31 Rechler M M, Nissley S P. Insulin-like growth factors. Peptide growth factors and their receptors. In: Sporn M B, Robbers A B, eds. Insulin-like growth factors. New York: Springer-Verlag, 1990; 263-367.

32 Ullrich A, Gray A, Tam A W, et al. Insulin-like growth factor 1 receptor primary structure: comparison with insulin receptor suggests structural determinants that define functional specificity. $E M B O f 1986 ; 5: 2503-12$.

33 Dore S, Pelletier J-P, DiBattista J A, Tardif G, Brazeau P Martel-Pelletier J. Human osteoarthritic chondrocytes possess an increased number of insulin-like growth factor possess an increased number of insulin-like growth factor
1 binding sites but are unresponsive to its stimulation: Possible role of IGF-1 binding proteins. Arthritis Rheum 1994; 37: 253-63.

34 Verschure P J, van Marle J, Joosten L A B, Van den Berg W B. Localization and quantification of the insulin-like growth factor-1 receptor in mouse articular cartilage by confocal laser scanning microscopy. 7 Histochem Cytochem 1994; 42: 765-73.

35 Brackertz D, Mitchell G F, Mackay T R. Antigen-induced arthritis in mice. Arthritis Rheum 1977; 20: 841-50.

36 Van den Berg W B, Kruijsen M W M, Van de Putte L B A. The mouse patella assay: an easy method of quantitating articular cartilage chondrocyte function in vivo and in vitro. Rheumatol Int 1982; 1: 165-9.

37 Kruijsen $M$ W $M$, Van den Berg W $B$, Van de Putte L B A, Van den Broek W J M. Detection and quantification of experimental joint inflammation in mice by measurement of $99 \mathrm{mTc}$-pertechnetate uptake. Agent Actions 1981; 11: 640-2.

38 De Vries B J, Van den Berg W B, Vitters E, Van de Putte L B A. Quantification of glycosaminoglycan metabolism in anatomically intact articular cartilage of the mouse
patella: in vitro and in vivo studies with ${ }^{35} \mathrm{~S}$ sulfate, ${ }^{3} \mathrm{H}$ glucosamine and ${ }^{3} \mathrm{H}$ acetate. Rheumatol Int 1986; 6: 273-81.

39 Altman F P. Gelatin embedding technique as an aid in the preparations of unfixed cryostat sections. Histochem $\mathcal{f}$ preparations of unfi

40 Johnstone J, Bitensky L, Chayen J. Cryostat sections of undemineralized bone. 7 Clin Pathol 1972; 25: 742 .

41 undemineralized bone. Clin Pathol $1972 ; 25: 742$. mineralized bone sections: the Bright bone cryostat. $f$ Clin Pathol 1972; 25: 26-9.

42 Rijntjes N V M, Van de Putte L A B, Van der Pol M, Guelen P J M. Cryosectioning of undecalcified tissues for immunofluorescence. F Immunol Methods 1979; 30: 263-8.

43 Van Noorden C J F, Vogels I M C. Enzyme histochemical reactions in unfixed and undecalcified cryostat sections of mouse knee joints with special reference to arthritic lesions. Histochemistry 1997; 86: 127-33.

44 Oemar B S, Foellmer H G, Hodgedon-Anandant L, Rosenzweig S A. Regulation of insulin-like growth facto receptors in diabetic mesangial cells. F Biol Chem 1991; 266: 2369-73.

45 Rosenzweig S A, Zetterstrom C, Benjamin A. Identification of retinal insulin receptors using site-specific antibodies to 
a carboxyl-terminal peptide of the human insulin receptor alpha-subunit. Upregulation of neuronal insulin receptors in diabetes. F Biol Chem 1990; 265: 18030-4.

46 White J G, Amos W B, Fordham M. An evaluation of confocal versus conventional imaging of biological structures by fluorescence light microscopy. $\mathcal{F}$ Cell Biol 1987; 105: 41-8.

47 Wotton S F, Jeacocke R E, Maciewicz R J, Wardale R J, Duance V C. The application of scanning confocal microDuance $V$ C. The application of scanning confocal micro-
scopy in cartilage research. Histochem $\mathcal{f}$ 1991; 23: scopy in 2835 .

48 Good M J, Hage W J, Mummery C L, De Laat $S$ W, Boonstra J. Localization and quantification of epidermal growth factors on single cells by confocal laser scanning microscopy. I Histochem Cytochem 1992; 40: 1353-61.

49 Van Beuningen H M, Van der Kraan P M, Arntz O J, Van den Berg W B. Protection against interleukin-1-induced articular cartilage damage by transforming growth factor$\beta_{1}$ : studies in anatomically intact cartilage in vitro and in vivo. Ann Rheum Dis 1993; 53: 185-91.

50 Aydelotte M B, Keuttner K E. Heterogeneity of articular chondrocytes and cartilage matrix. In: Woessner J F, howell D S, eds. Cartilage degradation: basic and clinical aspects. New York: Marcel Dekker, 1993; 37-65.

51 Maroudas A, Schneiderman R, Weinberg C, Grusko G. Choice of specimens in comparative studies involving human femoral head cartilage. In: Maroudas A, Keuttner K, eds. Methods in cartilage research. London: Academic Press, 1990; 9-17.

52 Siczkowski M, Watt F M. Subpopulations of chondrocytes from different zones of pig articular cartilage. Isolation growth and proteoglycan synthesis in culture. $\mathcal{F} \mathrm{Cell} S \mathrm{Sci}$ 1990; 97: 349-60.

53 Sampson H W, Cannon M S. Zonal analysis of metabolic profiles of articular-epiphyseal cartilage chondrocytes: a histochemical study. Histochem f 1984; 18: 233-8.

54 Meachim G, Ghadially F N, Collins D H. Regressive changes in the superficial layers of human articular changes in the superficial layers of hu

55 Dunham J, Shackleton D R, Bilingham M E J, Bitensky L, Chayen J, Muir H I. Altered orientation of glucosaminoglycans and cellular changes in tibial cartilage the first two weeks of experimental osteoarthritis. $\mathcal{F}$ Orthop Res 1985; 3: 258-69.

56 Middleton J F S, Tyler J A. Upregulation of insulin-like growth factor 1 gene expression in the lesions of osteo- arthritic human articular cartilage. Ann Rheum Dis 1992; 51: 440-7.

57 Rosenfeld R G. Characterization of the somatomedinC/insulin-like growth factor 1 (SM-C/IGF-1) receptor on cultured human fibroblast monolayers. Regulation of receptor concentrations by SM-C/IGF-1 and insulin. f Clin Endocrinol Metab 1982; 55: 434-40.

58 Rosenfeld R G, Hintz $R$ L. Characterization of a specific receptor for somatomedin $C$ (SM-C) on cultured human lymphocytes: evidence that $S M-C$ modulates homologous lymphocytes: evidencet that SM-C modulates homologous
receptor concentration. Endocrinology 1980; 107: receptor $1841-8$.

59 Sachs D H, Kiszkiss P, Kim K J. Release of la antigens by a cultured B cell line. F Immunol 1980; 124: 2130.

60 Porteu F, Nathan C. Shedding of tumor necrosis factor receptors by activated human neutrophils. $\mathcal{I}$ Exp Med 1990; 172: 599-607.

61 Altman F P. A metabolic dysfunction in early murine osteoarthritis. Ann Rheum Dis 1981; 4: 303-6.

62 Van Noorden C J F, Smith R E, Rasnick D. Cysteine proteinase activity in arthritic rat knee joints and the I Rheumatol 1988; 15: 1525-35.

63 Van Noorden C J F, Vogels I M C, Smith R E. Localization and cytochemical analysis of cathepsin B activity in and cytochemical analysis of cathepsin B activity in unfixed and undecalcified cryostat sections of whole
knee joints. F Histochem Cytochem 1989; 37: 617-24.

64 Joosten L A B, Helsen M A, Van den Berg W B. Transient chondrocyte non-responsiveness to insulin-like growth factor-1 upon $\mathrm{H}_{2} \mathrm{O}_{2}$ exposure is not related to IGF-1 receptor damage. I Rheumatol 1991; 18: 585-90.

65 Kato H, Faria T N, Stannard B, et al. Paradoxical biological effects of overexpressed insulin-like growth factor-1 receptors in Chinese hamster ovary cells. I Cell Physiol 1993; 156: 145-52.

66 Verschure P J, Joosten L A B, Van der Kraan P M, Van den Berg W B. Responsiveness of articular cartilage from normal and inflamed mouse knee joints to various growth factors. Ann Rheum Dis 1994; 53: 455-60.

67 Baici A. Arthritis from a biochemical aspect. Ther Umsch 1991; 48: 13-7.

68 Tesch H G, Handley C J, Cornell H J, Herrington A C. Effects of free and bound insulin-like growth factors on proteoglycan metabolism in articular cartilage explants. f Orthop Res Soc 1992; 10: 14-22.

69 Baxter R C. Circulating binding proteins for the insulin-like growth factors. Trends Endocrinol Metabol 1993; 4: 91-6. 